This PDF is a selection from a published volume from the National Bureau of Economic Research

Volume Title: Law and Employment: Lessons from Latin American and the Caribbean

Volume Author/Editor: James J. Heckman and Carmen Pagés, editors

Volume Publisher: University of Chicago Press

Volume ISBN: 0-226-32282-3

Volume URL: http://www.nber.org/books/heck04-1

Conference Date: November 16-17, 2000

Publication Date: August 2004

Title: Labor Market Policies and Employment Duration. The Effects of Labor Market Reform in Argentina

Author: Hugo Hopenhayn

URL: http://www.nber.org/chapters/c10076 


\title{
Labor Market Policies and Employment Duration The Effects of Labor Market Reform in Argentina
}

\author{
Hugo A. Hopenhayn
}

\section{Introduction}

Over the last few years, the debate on labor market reform has been at the center of economic policy debate in Argentina. This debate has been fueled by the sustained growth in the unemployment rate observed during the decade. One of the major targets of the attack on labor market regulation has been high dismissal costs. ${ }^{1}$

Attempts to reduce dismissal costs for all existing jobs have faced strong opposition. As a compromise, and to stimulate job creation, employment promotion contracts for new jobs were introduced in 1995. These contracts are limited to a fixed term ranging from three months to two years.

It is a standard view that the reform stimulated the creation of a large number of these temporary contracts, which currently dominate the flow of new jobs. However, there is now a growing concern about the volatility of these temporary jobs, referred to as junk contracts, and a predominant view that they tend to generate excessive turnover. This chapter studies the effect of this reform on job duration. ${ }^{2}$

Our main findings are that the reform generated an overall increase in the hazard rate, and particularly so for the first three months of employment. During this period, the average hazard rate increased by almost 40

Hugo A. Hopenhayn is professor of economics at the University of California, Los Angeles.

1. For an analysis of the effects of job security provisions on employment and reallocation, see Blanchard and Portugal (2001), Hopenhayn and Rogerson (1993), Nickell (1997), and Pagés and Montenegro (1999).

2. Blanchard and Landier (2001) find that temporary contracts in the French labor market increased turnover but not employment. Similar results for Spain are reported in Saint-Paul (2000). 
percent. For tenure above three months, the increase was on the order of 10 percent.

\subsection{Recent Changes in Labor Market Legislation}

During the 1990-1999 decade, there were two major changes in labor market legislation. These have not been major reforms, but rather they introduced flexibility at the margin by creating fixed-term and temporary contracts that eliminate or reduce dismissal costs and labor taxes.

The original law (1976) specified mandated severance payments equivalent to one month of salary per year of seniority. Changes were introduced in December 1991 and March 1995.

\subsubsection{The 1991 Reform}

This reform introduced fixed-term contracts and special-training contracts for young workers. Fixed-term contracts to promote employment were subject to the following terms:

- Applicability is restricted to workers who are registered in the national employment office as unemployed or laid off as a consequence of government employment cutbacks.

- The minimum duration is six months. The minimum renewal period is six months. The maximum total duration is eighteen months.

- Severance payment is determined in two ways. If the contract expires, the payment consists of half one month's salary. If the contract is terminated before expiration, the previous law applies.

- A reduction in labor taxes means that employer contributions are reduced from 33 percent to less than 20 percent.

Fixed-term contracts for new activity involved a somewhat different set of conditions.

- Applicability is restricted to new establishments or new lines of production or services in existing establishments.

- The minimum duration is six months. The minimum renewal period is six months. The maximum total duration is twenty-four months.

- Severance payment is determined in the same ways as for fixed-term contracts to promote employment.

- The same reduction in labor taxes applies as for fixed-term contracts to promote employment.

The most distinct category consisted of training-promotion contracts, which featured the following conditions:

- Applicability is limited to workers less than twenty-four years old.

- Duration varies from a minimum of four months to a maximum of twenty-four months. 
- There is no severance payment.

- There are no labor taxes.

It appears that this reform did not have a great impact. The law required approval by trade unions in order for these contracts to apply. The monthly flow of new employment promotion contracts registered at the employment office (which was a requirement) totaled less than 5,000 for the whole country.

\subsubsection{The 1995 Reform}

This reform introduced a trial period for all contracts, special contracts to promote the employment of certain age groups, and a special regime for small firms. The trial period provision introduced the following conditions:

- Applicability to all new contracts

- Duration of three months

- No severance payments for terminations within this period

- Tax reduction for employee from 20 percent to less than 8 percent, and tax reduction for employer from 33 percent to approximately 10 percent

Special employment promotion contracts:

- They are applicable to workers more than forty years old, who are not required to register in government employment offices.

- The minimum duration is six months; the minimum renewal period is six months; the maximum duration is twenty-four months.

- There is no severance payment at termination of contract. Standard severance payment applies for early termination.

- For labor taxes, employer contributions are reduced from 33 percent to less than 20 percent.

Training contract conditions are similar to previous law for unemployed workers between fourteen and twenty-five years of age.

In the case of small firms, the law establishes that these firms can use the employment promotion contracts from the previous law (described previously) with the following added advantages:

- No previous approval of the trade unions is required.

- There is no need to register the contract in the government employment agency.

- There is no severance payment.

\subsection{General Trends during the Period}

The period considered has been marked by a sizable increase in unemployment rates, starting at 7.5 percent in the beginning of the decade, 


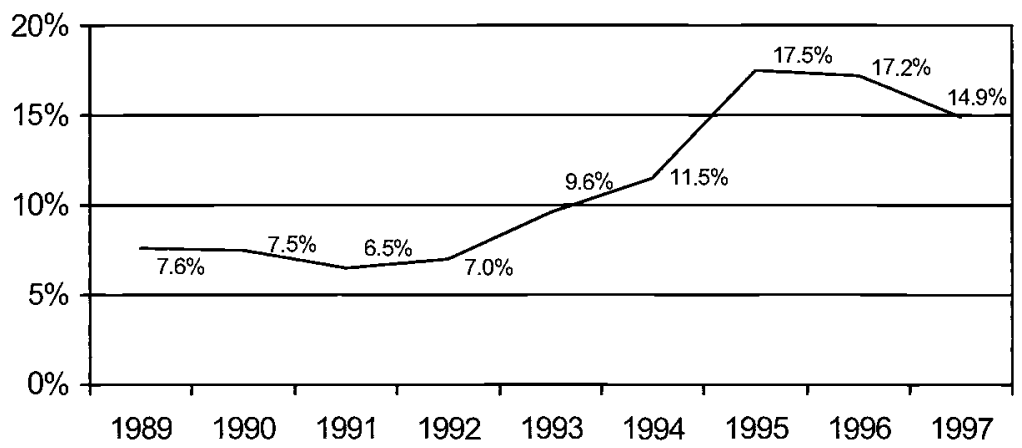

Fig. 9.1 Unemployment rate: Greater Buenos Aires region

Source: Ministerio de Economía, INDEC—May surveys.

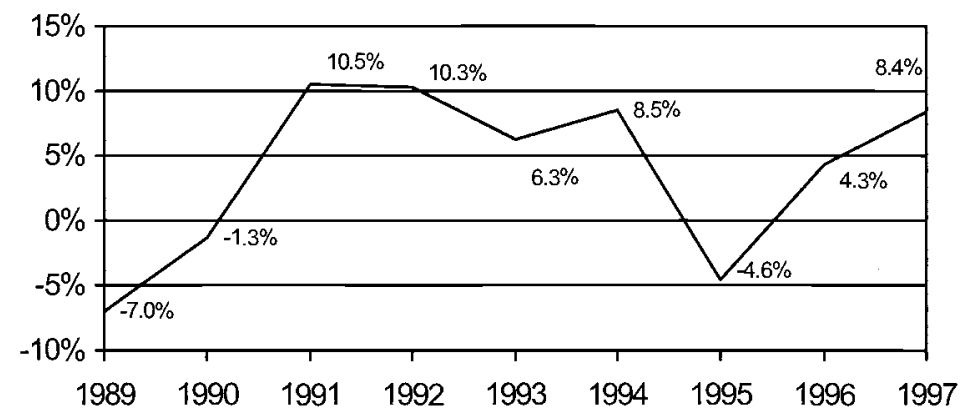

Fig. 9.2 GNP growth: Constant prices 1986

Source: Ministerio de Economía, INDEC.

peaking in May 1995 at 20 percent, and staying around 17 percent in the most recent surveys. Although part of this increase is explained by an upward trend in participation, most is accounted for by unemployment of existing labor market participants. Figure 9.1 gives an account of this evolution since 1993. As far as the business cycle is concerned, fluctuations have been large in the period, averaging out to a 3.7 percent growth rate. As seen in figure 9.2, the first two years of our study correspond to a big recession that is followed by three years of high growth rates. A new sharp recession occurs in 1995, also followed by a period of high growth.

Figures 9.3 and 9.4 provide standard estimates of creation and destruction flows for job matches. The rate of match creation is measured by the ratio of employed workers with less than one month (or six months) of tenure to the stock of employed workers. The rate of destruction is measured by taking the ratio of unemployed workers with less than one month (or six months) duration to the stock of employed workers.

These flows are fairly constant up to 1994. The severe recession in 1995 


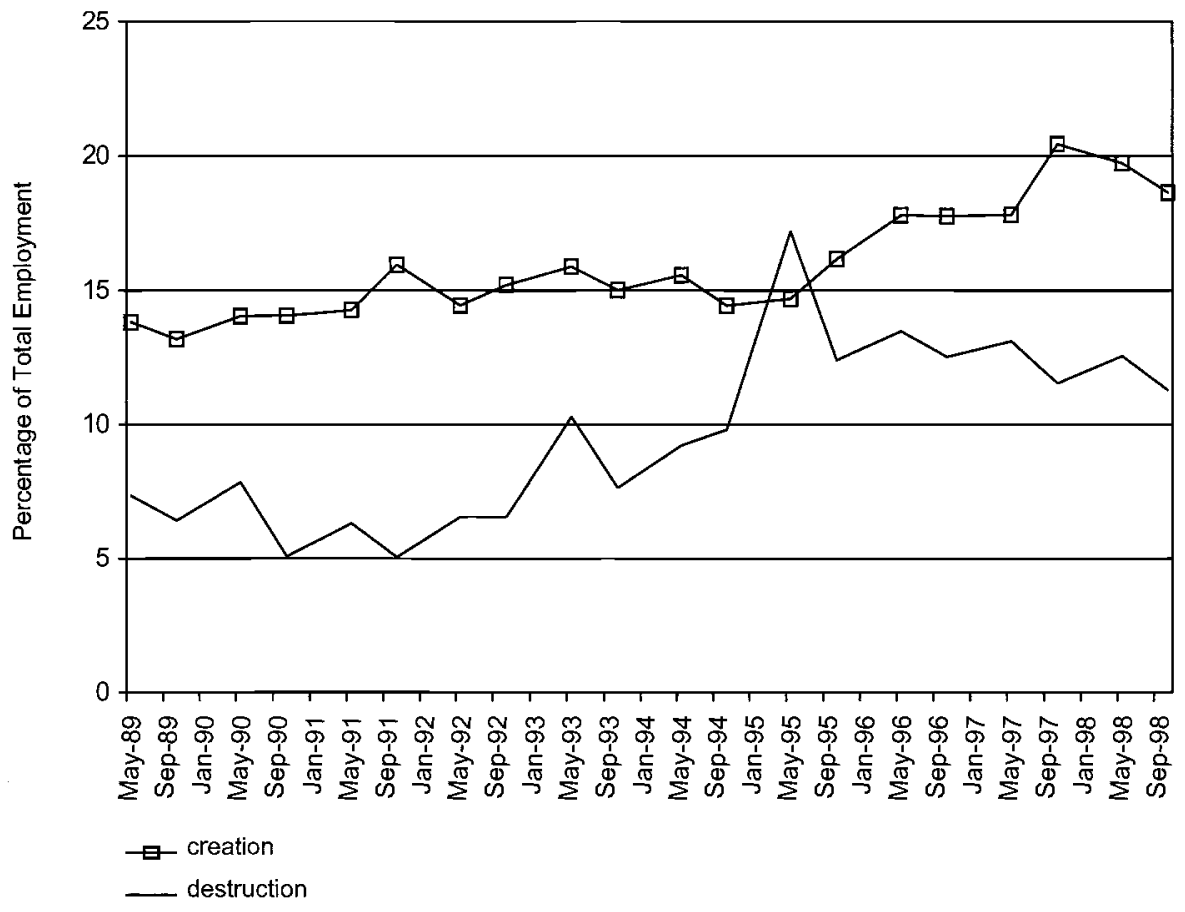

Fig. 9.3 Match creation and destruction: Six months

results in a large shock to match destruction, which is then followed by a steady increase in creation. After 1995, both flows stay at values at least 50 percent larger than those experienced during the first part of this decade. The breakpoint (1995) is a recession year, but also the beginning of the new labor market regime. In what follows, we attempt to identify the impact of this regime change.

\subsection{The Sample}

We use a linked panel of household survey data for the area of the Federal District and surroundings (Gran Buenos Aires), which amounts to approximately 60 percent of total Argentinean employment. The survey is conducted every six months (April/May and October) with a 25 percent rotation of the panel. As a consequence, each household can - in principlebe followed for two years at intervals of six months. Our sample consists of the linked panels from May 1989 to October 1998. There are a total of approximately 64,000 individuals in the sample, evenly distributed throughout the years, of whom over 44,000 have multiple observations. Based on these observations, our sample comprises a total of over 93,000 transition 


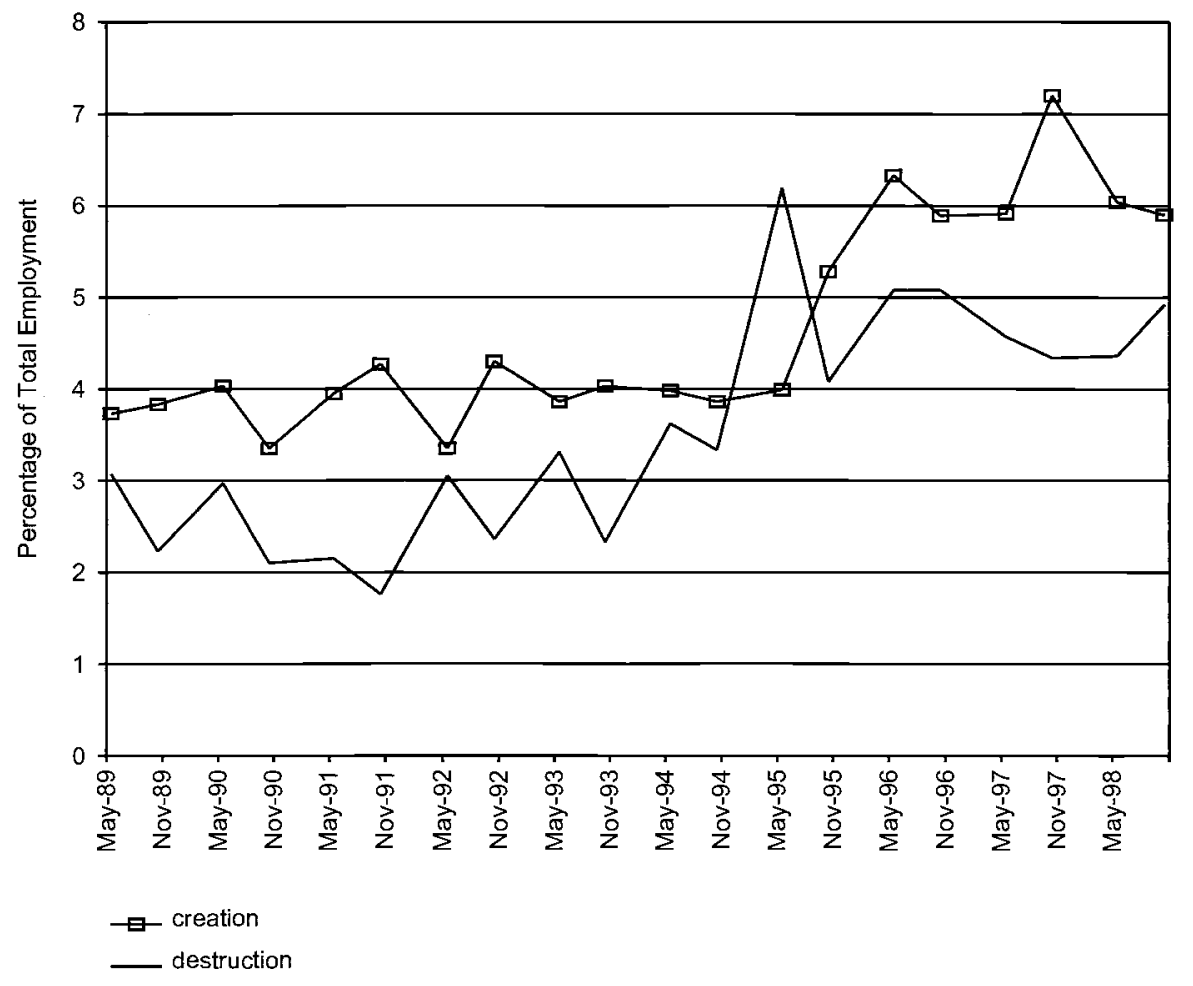

Fig. 9.4 Match creation and destruction: One month

pairs. After restricting the sample to those individuals between twenty-one and sixty-five years old, we are left with a total of approximately 71,000 transition pairs. Our conditional likelihood estimates consider only those individuals with initial tenure under five years who are still in the labor force the following period. This leaves a total of 14,854 transitions.

\subsubsection{Variables Used}

The variables considered were the following: ${ }^{3}$

- Personal characteristics such as sex, age, and education

- Job characteristics, including

- type of employment (salaried worker or self-employed)

- size of firm

- benefits received (social security contributions, paid vacations, extra month supplement, severance payment, and unemployment insurance)

3. For a list of variables included in this survey, see INDEC (2001). 
- duration of current job (if employed) or duration of unemployment spell (if unemployed)

We restrict our analysis to salaried employment, thus excluding the selfemployed, entrepreneurs, or family workers, who are not subject to the above regulations.

\subsection{Measuring the Effect of Regulation on Employment Duration}

The 1995 reform provides a natural experiment that can be used to evaluate the impact of changes in regulation. Overall, one might expect an increase in the flows into and out of employment, as a consequence of the availability of short-term contracts, which we quantify in the following. Given the three-month limit to temporary contracts, one might also expect to see a peak in the hazard rates at this term. The special regime for small firms provides another source for a natural experiment. In particular, one might expect a peak in the hazard rates for employment termination to appear at the point of expiration of the employment promotion contracts (twenty-four months), as well as at times of renewal (every six months).

\subsection{Methodological Considerations}

\subsubsection{Stock Sampling versus Flow Sampling}

Our panel data allow us to compute conditional probabilities for transitions out of employment, thus avoiding the problem of stock sampling. Correspondingly, our specification of hazard rates allows for duration dependence.

\subsubsection{Interval Censoring}

The panel's sampling plan presents the problem of interval censoring. Consider two consecutive surveys, which take place at time $t$ and $t+\Delta$, where $\Delta$ corresponds to the six months interval. The survey provides information on the agent's state of employment for each of these two periods and the elapsed duration in that state. Let $s_{i t}$ and $s_{i t+\Delta}$ denote the states and $d_{i t}$ and $d_{i t+\Delta}$ the corresponding elapsed durations. Take a worker who is employed in the first survey with elapsed duration $d_{0}$. Three things may happen in the following interval: (1) the worker is employed in the same job with duration $d_{1}=d_{0}+\Delta$; (2) the worker is in a new job with duration $d_{1}$ $<\Delta$; and (3) the worker is unemployed where $d_{1}<\Delta$ is the length of the current spell.

In cases (2) and (3), where a transition has occurred, it is impossible to determine exactly when the initial job was terminated, because there could have been multiple transitions. However, an upper bound for the duration 


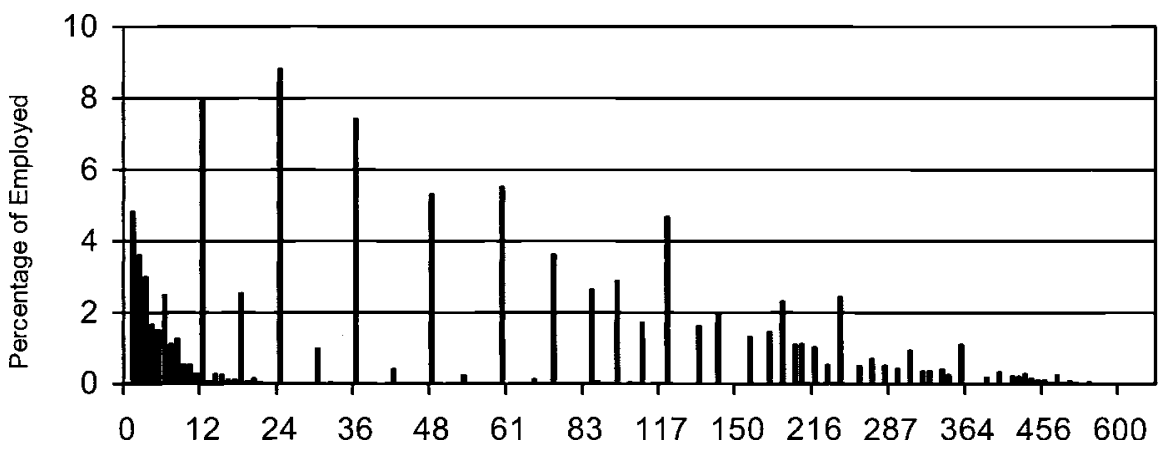

Fig. 9.5 Reported job tenure (in months)

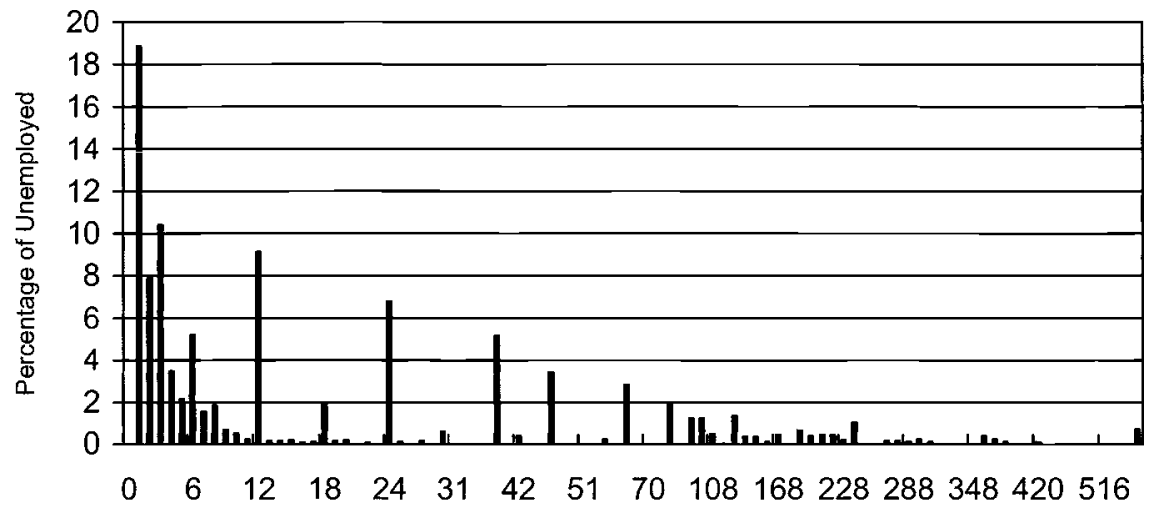

Fig. 9.6 Reported retrospective tenure (in months)

of the first job is given by $d_{0}+\Delta-d_{1}$, which would be exact if only one transition had taken place. The sample variation in $d_{1}$ for these workers is thus informative and contributes to identifying the underlying hazard rates. As usual, the observations from workers in case (1) can be treated as rightcensored observations. ${ }^{4}$

\subsubsection{Measurement Error in Duration Data}

As is well known, retrospective questions typically lead to significant reporting errors. In recalling the length of a current or past spell, individuals typically round off their elapsed duration. This gives rise to a common heaping problem where reports get concentrated at particular duration lengths, such as six months, one year, five years, ten years, and so on. This is illustrated in figures 9.5 and 9.6, which give, respectively, reported elapsed job tenure for employed workers and completed tenure in the last

\section{For an excellent discussion on interval censoring, see Magnac and Robin (1994).}


job for those unemployed, corresponding to all salaried workers in our sample. Unfortunately, some of these heaping times correspond to termination dates of certain contracts, making inference problematic. However, assuming that the distribution for reporting errors has not changed over time, the effect of changes in the duration of specific contracts can still be analyzed by looking at differences in hazard rates before and after the reform.

A second source of problems comes from the ambiguity in the question used to calculate job tenure for employed workers. The survey asks "How long have you been in this occupation?" Some respondents may interpret the occupation as a job description and not a particular match. Measurement error of this type is quite dramatic in our data. If we define a worker who has not changed jobs as one for which job tenure in the second interview exceeds six months, and if reports are correct in both intervals, job tenure should have increased by six months between the two surveys. Table 9.1 gives a distribution of the change in tenure for all workers, those with tenure less than one year, and those with tenure less than six months. As seen, only 5.6 percent of all matches (13.6 percent of those less than one year and 16 percent of those less than one month) satisfy this criteria. Notice that almost 24 percent of all reported changes in job tenure are negative (recall that we are excluding new jobs) and a similar amount report changes in tenure of over one year. The degree of inconsistency is less for workers with lower duration. Furthermore, for workers in this class, a large fraction hold new jobs (less than six months of tenure).

Measurement error is probably less of a problem for identifying when an individual has changed from one state to another (employment to unem-

Table 9.1

Changes in Reported Tenure

\begin{tabular}{|c|c|c|c|c|c|c|}
\hline \multirow[b]{2}{*}{ Change in Tenure } & \multicolumn{2}{|c|}{ All Workers } & \multicolumn{2}{|c|}{ Tenure $<1$ Year } & \multicolumn{2}{|c|}{ Tenure $<6$ Months } \\
\hline & $\%$ & Cumulative $\%$ & $\%$ & Cumulative $\%$ & $\%$ & Cumulative $\%$ \\
\hline Less than 0 & 23.7 & 23.7 & 1.7 & 1.7 & 0 & 0 \\
\hline 0 & 22.7 & 46.4 & 8.0 & 9.7 & 0 & 0 \\
\hline 1 & 0.2 & 46.6 & 0.8 & 10.5 & 0.5 & 0.5 \\
\hline 2 & 0.5 & 47.1 & 1.9 & 12.5 & 1.1 & 1.6 \\
\hline 3 & 0.6 & 47.7 & 2.3 & 14.8 & 1.5 & 3.1 \\
\hline 4 & 1.2 & 48.8 & 4.8 & 19.6 & 4.6 & 7.7 \\
\hline 5 & 1.3 & 50.1 & 6.1 & 25.7 & 7.1 & 14.8 \\
\hline 6 & 5.6 & 55.7 & 13.6 & 39.4 & 16.0 & 30.9 \\
\hline 7 & 1.1 & 56.8 & 5.1 & 44.5 & 8.8 & 39.7 \\
\hline 8 & 0.9 & 57.6 & 3.8 & 48.3 & 6.3 & 46.0 \\
\hline 9 & 0.8 & 58.4 & 3.6 & 51.9 & 6.5 & 52.4 \\
\hline 10 & 0.7 & 59.1 & 2.8 & 54.7 & 4.5 & 56.9 \\
\hline 11 & 0.5 & 59.6 & 2.4 & 57.1 & 4.2 & 61.1 \\
\hline 12 & 16.3 & 75.9 & 10.7 & 67.9 & 1.7 & 62.8 \\
\hline
\end{tabular}


ployment or vice versa), for which there is a specific question in the survey. The measurement error is more critical in attempting to identify transitions within the same state, times of transition, and elapsed duration. Unless there has been a change of state, we adopt the convention of defining as a new spell one where tenure or unemployment duration in the second survey is less than or equal to six months. If the survey indicates a change of state and elapsed duration in the second state exceeds six months, we consider this a change of state with censored time of change.

\subsection{Flows in and out of Employment}

The panel data can be used to estimate total flows in and out of employment. The flows are calculated by considering all employed workers in a given survey and observing their state in the following survey period. The flow data thus constructed is pooled across all samples to compute the mean transition probabilities. All calculations were done for salaried workers. Figure 9.7 gives estimates corresponding to all transitions of employed workers into unemployment or a new job. Total flows out of em-

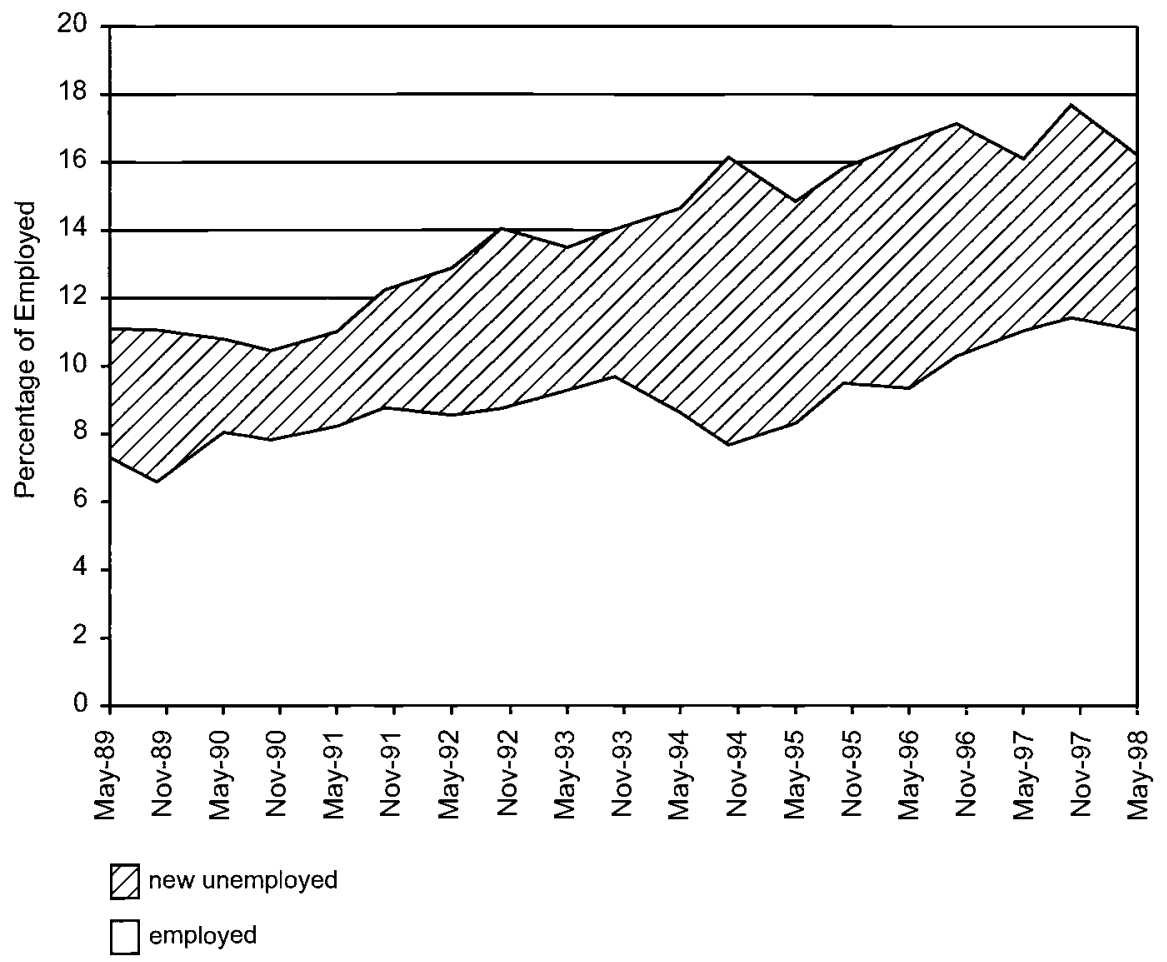

Fig. 9.7 Transitions from employment 


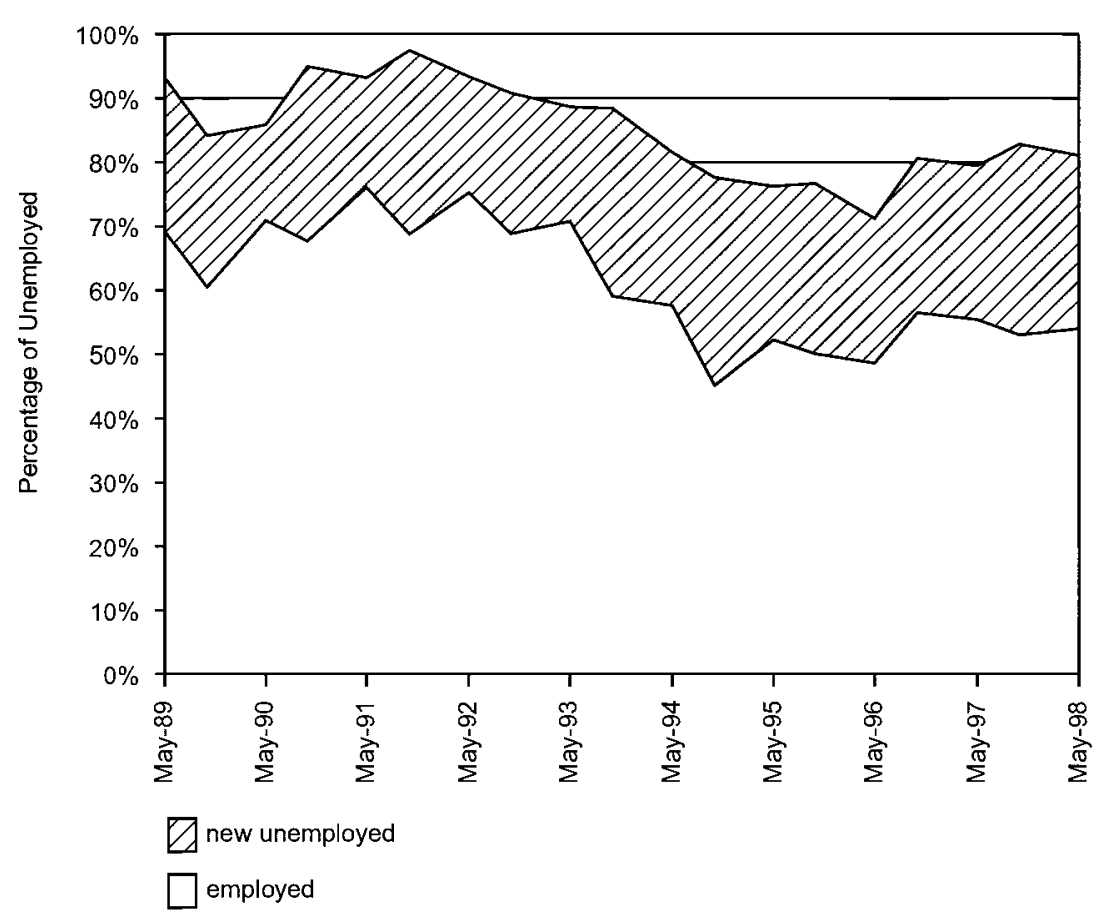

Fig. 9.8 Transitions from unemployment

ployment increased from approximately 10 percent at the beginning of our sample period to over 15 percent at the end. Both components of the outflow have increased, though in the last few years the growth comes mostly from changes to new jobs. ${ }^{5}$ Similar conclusions follow when considering transition flows for workers with short initial job tenure.

Figure 9.8 considers the flows out of unemployment. These have decreased during the sample period, particularly dominated by lower probabilities of being employed after the six month interval between surveys.

Table 9.2 gives hazard rates for total separation, classified by initial job tenure and for years prior to and after the 1995 reform. Most remarkably, these hazard rates exhibit a sharp increase for workers in low tenure brackets. In contrast, for workers with initial tenure over six months, there is no detectable change. This table also indicates that total separation rates are initially very high and decrease rapidly with tenure.

Table 9.3 gives the fraction of employed workers in each tenure bracket that ended unemployed in the following survey. The patterns are quite sim- 
ilar, with large increases after the reform for workers with initial tenure under three months. It is worth recalling that this duration corresponds to the time limit of temporary contracts. Overall, the transitions to unemployment are a small, but increasing, fraction of total separations. This could be the consequence of either high quits into new jobs or high rates of escape from unemployment. Estimates of the multiple-cycles model studied in the following indicate that the latter effect dominates.

Tables 9.4 through 9.9 provide decompositions of the previous two tables by age, benefits, and firm size. The following specific conclusions emerge:

Table 9.2

Hazard Rates for Total Separations (\%)

\begin{tabular}{lrr}
\hline Years & Before & After \\
\hline 0-1 month & 52.8 & 66.1 \\
1-3 months & 37.3 & 45.6 \\
3-6 months & 25.3 & 32.6 \\
6 months-1 years & 21.2 & 22.3 \\
1-2 years & 13.5 & 13.5 \\
2-5 years & 9.1 & 9.9 \\
Total & 13.1 & 15.7 \\
\hline
\end{tabular}

Table 9.3

Hazard Rates of Involuntary Separations (\%)

\begin{tabular}{lrr}
\hline Years & Before & After \\
\hline 0-1 month & 12.9 & 22.7 \\
1-3 months & 9.9 & 12.8 \\
3-6 months & 6.4 & 8.1 \\
6 months-1 year & 5.8 & 6.8 \\
1-2 years & 3.2 & 4.1 \\
2-5 years & 2.5 & 3.4 \\
Total & 3.5 & 5.0 \\
\hline
\end{tabular}

Table 9.4

Hazard Rates for Total Separations, by Age (\%)

\begin{tabular}{lccccccrr}
\hline & \multicolumn{2}{c}{ Younger than 25 } & & \multicolumn{2}{c}{$25-40$} & & \multicolumn{2}{c}{ Older than 40 } \\
\cline { 2 - 3 } Years & Before & After & & Before & After & & Before & After \\
\hline 0-1 month & 64.0 & 78.2 & & 48.0 & 60.0 & & 40.3 & 60.5 \\
1-3 months & 46.1 & 50.8 & & 35.4 & 42.9 & & 23.2 & 41.6 \\
3-6 months & 31.9 & 31.9 & & 22.0 & 38.9 & & 22.4 & 23.6 \\
6 months-1 year & 27.4 & 26.6 & & 19.5 & 20.0 & & 15.9 & 19.8 \\
1-2 years & 16.9 & 14.8 & & 11.5 & 13.6 & & 13.1 & 11.8 \\
2-5 years & 11.3 & 15.6 & & 8.5 & 8.9 & & 8.4 & 7.5 \\
Total & 25.1 & 28.3 & & 12.6 & 15.4 & & 8.5 & 10.5 \\
\hline
\end{tabular}


Table 9.5

Hazard Rates of Involuntary Separations, by Age (\%)

\begin{tabular}{|c|c|c|c|c|c|c|}
\hline \multirow[b]{2}{*}{ Years } & \multicolumn{2}{|c|}{ Younger than 25} & \multicolumn{2}{|c|}{$25-40$} & \multicolumn{2}{|c|}{ Older than 40} \\
\hline & Before & After & Before & After & Before & After \\
\hline $0-1$ month & 14.4 & 30.7 & 11.2 & 16.9 & 12.9 & 20.9 \\
\hline $1-3$ months & 15.0 & 14.2 & 5.7 & 12.9 & 7.1 & 10.8 \\
\hline 3-6 months & 6.9 & 6.6 & 5.6 & 10.6 & 6.7 & 6.4 \\
\hline 6 months -1 year & 8.2 & 6.0 & 4.3 & 5.6 & 4.8 & 9.6 \\
\hline $1-2$ years & 2.3 & 5.0 & 2.2 & 4.0 & 5.4 & 3.3 \\
\hline $2-5$ years & 2.8 & 4.7 & 2.4 & 3.2 & 2.3 & 2.9 \\
\hline Total & 4.7 & 5.4 & 3.0 & 4.6 & 2.6 & 3.7 \\
\hline
\end{tabular}

Table 9.6

Hazard Rates of Total Separations, by Social Benefits (\%)

\begin{tabular}{lccccc}
\hline & \multicolumn{2}{c}{ No Benefits } & & \multicolumn{2}{c}{ All Benefits } \\
\cline { 2 - 3 } \cline { 5 - 6 } Years & Before & After & & Before & After \\
\hline 0-1 month & 53.3 & 68.7 & & 46.9 & 48.3 \\
1-3 months & 44.4 & 48.9 & & 25.4 & 38.2 \\
3-6 months & 27.1 & 39.5 & & 23.5 & 20.9 \\
6 months-1 year & 24.3 & 27.3 & & 16.1 & 16.5 \\
1-2 years & 16.7 & 19.9 & & 10.0 & 7.3 \\
2-5 years & 11.2 & 12.3 & & 8.3 & 7.8 \\
Total & 17.0 & 22.9 & & 9.2 & 8.6 \\
\hline
\end{tabular}

Table 9.7

Hazard Rates of Total Separations, by Firm Size (\%)

\begin{tabular}{lccccc}
\hline & \multicolumn{2}{c}{ Small Firms } & & \multicolumn{2}{c}{ Large Firms } \\
\cline { 2 - 3 } \cline { 5 - 6 } Years & Before & After & & Before & After \\
\hline 0-1 month & 51.0 & 66.3 & & 58.7 & 65.3 \\
1-3 months & 39.0 & 47.8 & & 31.5 & 38.3 \\
3-6 months & 24.4 & 34.0 & & 28.0 & 28.5 \\
6 months-1 year & 21.7 & 22.8 & & 19.4 & 20.7 \\
1-2 years & 14.5 & 14.8 & & 10.8 & 10.1 \\
2-5 years & 9.4 & 11.2 & & 8.3 & 6.7 \\
Total & 13.9 & 17.7 & & 11.2 & 11.0 \\
\hline
\end{tabular}

1. The increase in the hazard rate is larger for employees with no benefits. This may actually be explained by the fact that workers on employment promotion contracts - such as the trial period - do not get benefits. Indeed, as we will see later, the share of the flow out of employment due to termination of temporary contracts increased significantly after the reform. 
Table 9.8

Hazard Rates of Involuntary Separations, by Social Benefits (\%)

\begin{tabular}{lccrrr}
\hline & \multicolumn{2}{c}{ No Benefits } & & \multicolumn{2}{c}{ All Benefits } \\
\cline { 2 - 3 } \cline { 5 - 6 } Years & Before & After & & Before & After \\
\hline 0-1 month & 12.7 & 24.4 & & 10.2 & 12.1 \\
1-3 months & 10.9 & 13.9 & & 8.5 & 11.6 \\
3-6 months & 7.1 & 8.7 & & 5.9 & 7.1 \\
6 months-1 year & 6.6 & 8.3 & & 4.3 & 5.5 \\
1-2 years & 4.1 & 5.8 & & 1.8 & 2.3 \\
2-5 years & 2.5 & 3.8 & & 2.8 & 3.0 \\
Total & 2.1 & 2.8 & & 2.6 & 3.0 \\
\hline
\end{tabular}

Table 9.9

Hazard Rates of Involuntary Separations, by Firm Size (\%)

\begin{tabular}{lrrrrr}
\hline & \multicolumn{2}{c}{ Small Firms } & & \multicolumn{2}{c}{ Large Firms } \\
\cline { 2 - 3 } \cline { 5 - 6 } Years & Before & After & & Before & After \\
\hline 0-1 month & 13.0 & 23.2 & & 12.7 & 20.4 \\
1-3 months & 10.4 & 12.8 & & 8.1 & 13.0 \\
3-6 months & 6.3 & 8.8 & & 6.5 & 6.0 \\
6 months-1 year & 5.4 & 6.5 & & 6.9 & 8.0 \\
1-2 years & 3.4 & 4.7 & & 2.5 & 2.8 \\
2-5 years & 2.5 & 4.2 & & 2.4 & 1.7 \\
Total & 3.5 & 5.6 & & 3.4 & 3.4 \\
\hline
\end{tabular}

2. The hazard rates separations in low-duration brackets increase more for the treatment groups (small firms, workers less than twenty-five and over forty). The difference is somewhat less pronounced when considering flows into unemployment. This suggests that workers in these targeted groups may be experiencing a fast turnaround from unemployment.

\subsection{Hazard Rate Estimation}

This section gives details on the methodology used to estimate hazard rates. ${ }^{6}$

\subsubsection{Estimation}

We construct a piecewise constant-baseline hazard function. Consider a grid of durations $\left\{0=t_{0}<t_{1}<\ldots<t_{j}\right\}$, and for $j=1, \ldots, J$ let $\Delta_{j}=t_{j}-$

6. Hazard function models have been extensively used in the economic literature over the last two decades (compare, e.g., Lancaster [1990] and Heckman and Singer [1984]). 
$t_{j-1}$, denote the length of each of the corresponding $J$ intervals. Hazard rates are assumed constant within each interval. Let $J(t)=\max \left\{j \mid t_{j}<t\right\}$, so that $t_{J(t)} \leq t<t_{J(t)+1}$.

Given vectors of covariates $\mathbf{x}=\left(\mathbf{x}_{1}, \mathbf{x}_{2}\right)$ and parameters $\boldsymbol{\beta}=\left(\boldsymbol{\beta}_{0}\right.$, $\left.\left\{\boldsymbol{\beta}_{j}\right\}_{j=1, \ldots, J}\right)$, the hazard rate is given by

$$
h(t ; \mathbf{x}, \boldsymbol{\beta})=g\left(\mathbf{x}_{1}, \boldsymbol{\beta}_{0}\right) h_{J(t)}\left(\mathbf{x}_{2}, \boldsymbol{\beta}_{J(t)}\right) .
$$

This is a hybrid model, where some covariates $\left(\mathbf{x}_{1}\right)$ affect the hazard rate proportionately, while the remaining covariates $\left(\mathbf{x}_{2}\right)$ affect each segment separately. As an example, taking one of the dummy variables to be the indicator of the years with temporary contracts, this formulation allows us to study the effect these contracts had on different segments of the hazard rate.

Given the above specification, the survival function $S(t)$ satisfies

$$
S(t ; \mathbf{x}, \boldsymbol{\beta})=\exp \left\{-g\left(\mathbf{x}_{1}, \boldsymbol{\beta}_{1}\right)\left[\sum_{1 \leq j \leq J(t)-1} h_{j}\left(\mathbf{x}_{2}, \boldsymbol{\beta}_{2 j 1}\right) \Delta_{j}+h_{J(t)}\left(\mathbf{x}_{2}, \boldsymbol{\beta}_{2 j 1}\right)\left(t-t_{J(t)}\right)\right]\right\} .
$$

Our data consists of employment spells that may have been completed or continued between two consecutive interviews. For both types of spells, we have information on elapsed duration at the time of the first interview, which we denote by $t_{0}$ months. In case of incomplete spells, elapsed duration in the second interval, $t_{1}$, is given by $t_{1}=t_{0}+6$ because the survey takes place every six months. In case of complete spells, the information is limited due to interval censoring. Letting $\delta$ denote the duration of the new spell (either a new job or unemployment), all we know is that $t_{1} \in\left[t_{0}, t_{0}+6-\delta\right]$.

The conditional probability of a continuing spell is given by $S\left(t_{0}+6\right) /$ $S\left(t_{0}\right)$, and the conditional probability of a completed spell is given by $\left(S\left[t_{0}\right]\right.$ $\left.-S\left[t_{0}+6-\delta\right]\right) / S\left(t_{0}\right)$. Letting $I_{0}$ denote the set of individuals with continuing spells and $I_{1}$ those with completed spells, the likelihood function is given by

$$
\begin{aligned}
\ln L(\mathbf{x}, \boldsymbol{\beta})= & \sum_{i \in I_{0}}\left[\ln S\left(t_{i}+6 ; \mathbf{x}_{i}, \boldsymbol{\beta}\right)-\ln S\left(t_{i} ; \mathbf{x}_{i}, \boldsymbol{\beta}\right)\right] \\
& +\sum_{i \in I_{1}}\left\{\ln \left[S\left(t_{i} ; \mathbf{x}_{i}, \boldsymbol{\beta}\right)-S\left(t_{i}+6-\delta ; \mathbf{x}_{i}, \boldsymbol{\beta}\right)\right] \ln S\left(t_{i} ; \mathbf{x}_{i}, \boldsymbol{\beta}\right)\right\} .
\end{aligned}
$$

Note that by restricting our estimates to conditional probabilities, we circumvent the problems associated to length bias sampling and nonstationarity of flows. This is also the reason why we have not included in our estimates the information of the elapsed length of the second spell for those individuals that completed the initial spell and were employed in a new job at the time of the second interview.

The specification used for the hazard functions is log-linear, so $g(\mathbf{x}, \boldsymbol{\beta})=$ $\exp \left(\boldsymbol{\beta}^{\prime} \mathbf{x}\right)$ and $h_{j}\left(\mathbf{x}, \boldsymbol{\beta}_{j}\right)=\exp \left(\boldsymbol{\beta}_{j}^{\prime} \mathbf{x}\right)$. 


\subsection{Results}

The following variables were included in the estimates:

\begin{tabular}{ll}
\hline Age & \multicolumn{1}{c}{ Measured in Years } \\
\hline Sex & 0 = female; 1 = male \\
Sch1 & Complete elementary school \\
Sch2 & Incomplete high school \\
Sch3 & Complete high school \\
Sch4 & Incomplete college \\
Sch5 & Completed college \\
Large firm & Dummy for more than 50 employees \\
Benefits & 0 = no benefits; 1 = some or all benefits \\
$95-98$ & Dummy for years 95-98 \\
\hline
\end{tabular}

Table 9.10 gives the mean hazard rates and survival function implied by our estimates. Note that hazard rates are quite large during the first few months and fall rapidly thereafter. Almost half of the jobs are terminated before three months, and approximately one-third reach one year. At that point, hazard rates are very low.

Table 9.11 gives the maximum likelihood estimates. For each set of regressions, there are three columns giving, respectively, the parameter estimates, the standard errors, and the risk ratios. Naturally, the latter are only given for dummy variables. The demographic covariates are highly significant and have similar values across the three specifications. Age decreases the hazard rate at a rate of 1.3 percent per year. Male workers face a 20 percent higher risk of termination. Higher schooling reduces the risk of job termination. In particular, college graduates have half the risk of those workers with no complete elementary education. Employment in a large firm results in a mild (but significant) reduction in this risk. Finally, workers with informal labor contracts (those perceiving no benefits) have twice as high a risk of employment termination.

The first three columns correspond to estimates of a hazard function

Table 9.10 Survival Function and Hazard Rate

\begin{tabular}{lcc}
\hline Years & Survival Function & Hazard Rate $^{\mathrm{a}}$ \\
\hline 1 month & 1 & 0.326 \\
3 months & 0.542 & 0.158 \\
6 months & 0.361 & 0.023 \\
1 year & 0.323 & 0.023 \\
2 years & 0.258 & 0.016 \\
5 years & 0.162 & \\
\hline
\end{tabular}

${ }^{a}$ Hazard rates are monthly and constant in the interval defined by the given row and the following one.

${ }^{b}$ Duration is reported by months, so the minimum reported in the sample is one month. 


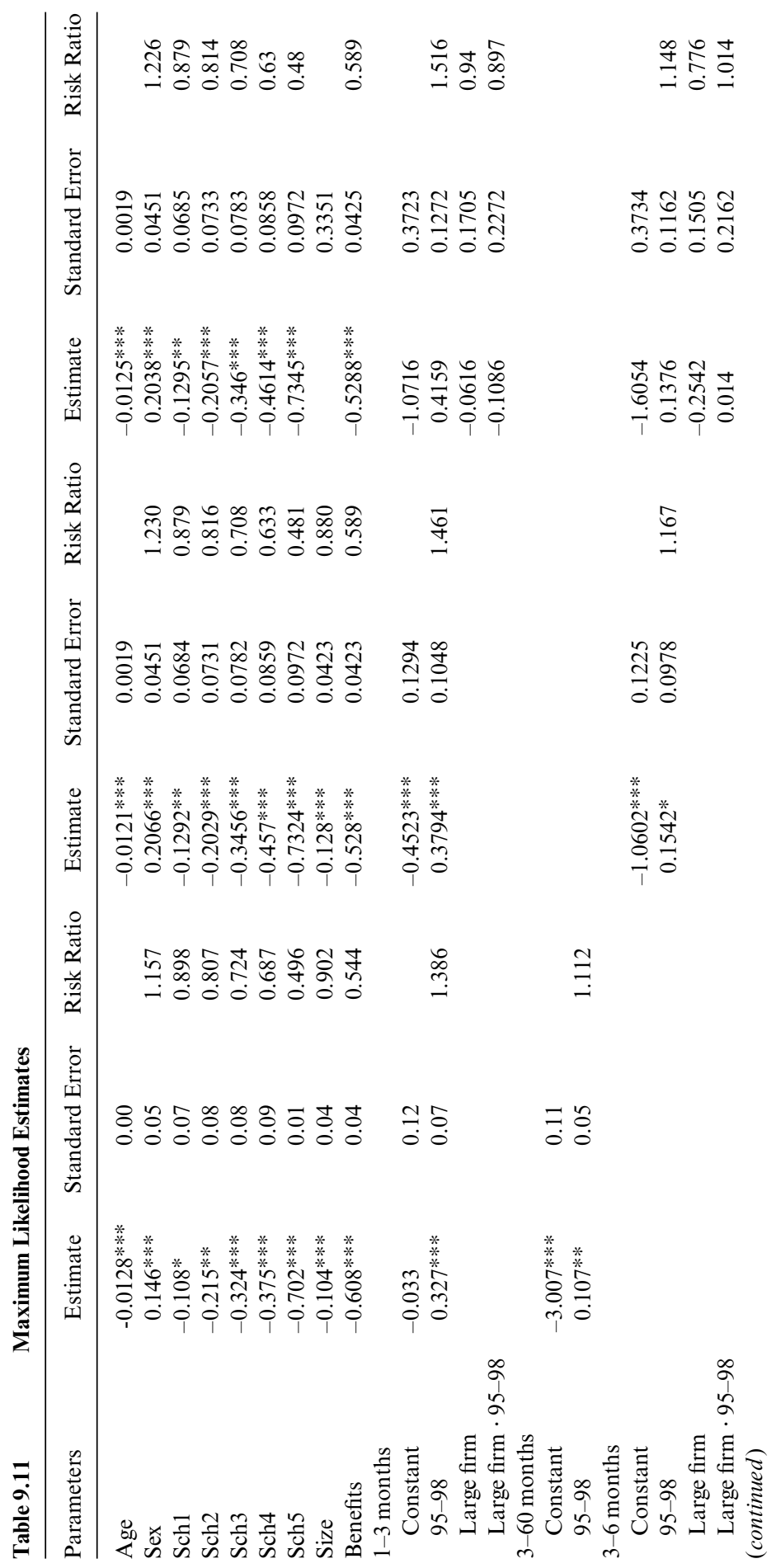




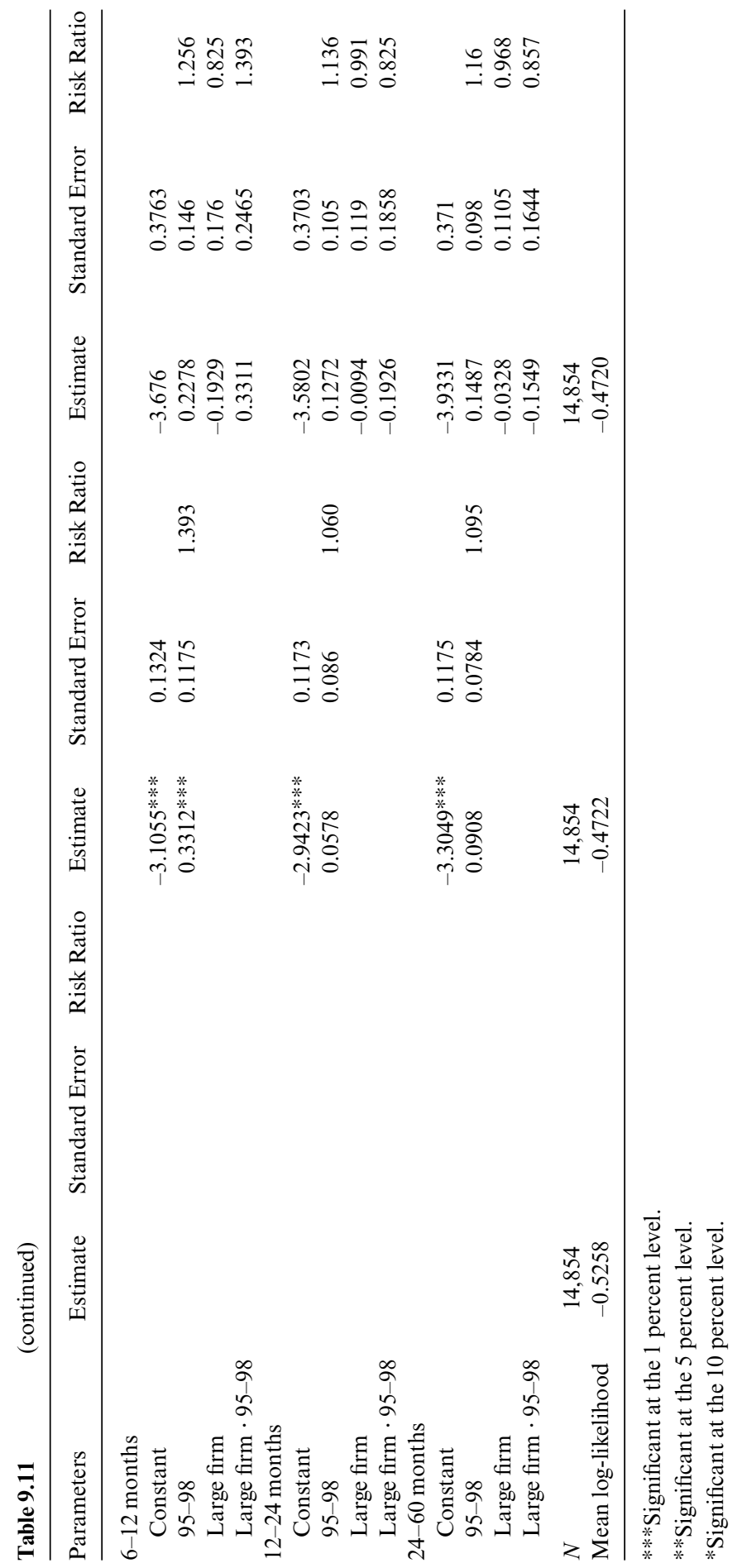


with two segments: elapsed duration of less than three months and elapsed duration of more than three months. Though it is plausible that policy changes affect all of the hazard function, the introduction of temporary contracts in 1995 is more likely to impact the first segment. Indeed, our estimates show this pattern: Hazard rates for the first three months rise by almost 40 percent after 1995, while the overall increase for jobs with longer tenure is around 10 percent. These parameters are estimated quite precisely, so this difference is significant.

The second specification provides a larger set of duration intervals. After 1995, hazard rates in the one- to three-month interval increase by more than 40 percent. For longer tenure brackets, the increase is not monotonic. Most remarkably, in the six- to twelve-month segment, the increase is also close to 40 percent. However, this increase applies to a much lower base: For the average individual in the sample, after 1995 hazard rates in the oneto three-month interval increase by 23 percentage points ( 33 percent to 46 percent), while for the six- to twelve-month interval, the increase represents less than 1 percentage point ( 2.3 percent to 3.2 percent).

The increase in hazard rates for jobs exceeding the three-month limit may seem perplexing. However, there is an explanation. Temporary contracts have two effects. On the one hand, it allows firms to terminate bad matches more rapidly. This selection effect leads to a decrease in hazard rates for the period following the end of a temporary contract. On the other hand, temporary contracts reduce the cost of turnover and thus the cost of experimenting with new matches. This can have a positive impact on overall hazard rates.

The third specification allows for the dummies of firm size and its interaction with 1995-1998 to affect selectively each segment of the hazard rate. This specification allows us to test the impact of the special regime for small firms introduced in 1995. None of the coefficients for these added variables turns out to be significant. Similar results were obtained when including dummy variables for age groups interacted with 1995-1998 in each of the segments. Thus, the evidence does not detect a significant impact of the special regimes for small firms and young workers.

\subsection{Final Remarks}

This chapter analyzes the impact of the 1995 labor market in Argentina. Our results show that this reform had a very strong impact on labor turnover, increasing hazard rates during the trial period by 40 percent, without a compensating decrease for longer tenure. In contrast, the special regimes for small firms and young workers show no sizable effects.

What is the economic significance of this response? The policies implied lower taxes for workers with temporary contracts, inducing an increase in hiring but also a substitution away from longer-term employment. Evalu- 
ating the costs of this type of distortion is obviously an important question. In addition, by reducing the cost of experiencing new matches, this policy may have contributed to a better allocation of workers to firms. As indicated by the increase in hazard rates for tenures beyond the limit of temporary contracts, firms seem to have reacted positively to this incentive.

A complete evaluation of the costs and benefits of these policies would require formulating and estimating a structural model of job matching. The results presented in this chapter suggest that research efforts in this direction can prove substantial.

\section{References}

Blanchard, O., and A. Landier. 2001. The perverse effects of partial labor market reform: Fixed duration contracts in France. NBER Working Paper no. 8219. Cambridge, Mass.: National Bureau of Economic Research, April.

Blanchard, O., and P. Portugal. 2001. What hides behind an unemployment rate: Comparing U.S. and Portuguese labor markets. American Economic Review 91 (1): 187-207.

Heckman, J., and B. Singer. 1984. Econometric duration analysis. Journal of Econometrics 24:63-112.

Hopenhayn, H., and R. Rogerson. 1993. Job turnover and policy evaluation: A general equilibrium analysis. Journal of Political Economy 101 (5): 915-38.

INDEC. 2001. Encuesta permanent de hogares: Base usuaria ampliada. Available at [http://www.indec.mecon.gov.ar.eph/May2001/Docs/Buadoc2.doc].

Lancaster, T. 1990. The econometric analysis of transition data. Econometric Society Monograph Series. Cambridge: Cambridge University Press.

Magnac, T., and J.-M. Robin. 1994. An econometric analysis of labour market transitions using discrete tenure data. Labour Economics 1:327-46.

Nickell, S. 1997. Unemployment and labor market rigidities: Europe versus North America. Journal of Economic Perspectives 11 (3): 55-74.

Pagés, C., and C. Montenegro. 1999. Job security and the age-composition of employment: Evidence from Chile. IADB Working Paper no. 398. Washington, D.C.: Inter-American Development Bank.

Saint-Paul, G. 2000. Flexibility vs. rigidity: Does Spain have the worst of both worlds? Universitat Pompeu Fabra Discussion Paper no. 144. Barcelona, Spain: Universitat Pompeu Fabra. 